\title{
VI
}

\section{AÇÕES DE ASTRONOMIA E SUAS INTERFACES COM A EDUCAÇÃO NÃO FORMAL EM UBERABA/MG*}

\author{
Adriano Ribeiro Sousa \\ Carlos Alberto Bielert Neto \\ Marcos Dionizio Moreira
}

\section{Considerações iniciais}

A Astronomia sempre despertou a curiosidade das pessoas. $\mathrm{O}$ céu estrelado em um local de pouca iluminação é deslumbrante, a Lua cheia iluminando a noite tem potencial de chamar a atenção até do mais desatento indivíduo. Além do deslumbramento, conhecer aspectos da Astronomia significava, por vezes, em civilizações mais remotas, ter ferramentas que possibilitaram a sobrevivência dos indivíduos, o

[...] ciclo das estações, a luz e o calor do Sol durante o dia, o luar e as estrelas à noite, a necessidade de se orientar em seus percursos de um lugar a outro e de estabelecer uma cronologia para os acontecimentos foram motivos suficientes para o homem tentar equacionar o Universo. (MILONE et al., 2010, p. 3)

Embora a Astronomia permeie toda a história da civilização, e muitos dos conceitos básicos desse conhecimento estejam no cotidiano das pessoas, nota-se que uma parcela significativa da população está à margem desse conhecimento ou conhece apenas versões errôneas ou baseadas em mitos (OLIVEIRA, VOELZKE e AMARAL, 2007). A pós-modernidade, com seus aparatos tecnológicos, hipnotiza os indivíduos com sua fácil comunicação e entretenimento. O prazer

*DOI - 10.29388/978-65-86678-24-6-0-f.117-134 
de uma caminhada para refletir sobre a vida e o observar a natureza parece terem perdido seus valores. Como relatado por Batista (2014, p. $35-36)$

Hoje, em nossa civilização moderna, as pessoas se esqueceram do céu, pois ficam reclusas em ambientes fechados quase que 24 horas por dia [...] O homem, imerso em sociedades globalizadas, dinâmicas e extremamente capitalistas não se preocupa mais em saciar a sua curiosidade com respeito ao céu, simplesmente ele o ignora como se não fizesse parte de sua vida. Esse fato fez com que o homem moderno assumisse como prioridade o seu lado pessoal e não o global. Faz com que ele pense somente em si mesmo e não na soci edade como um todo.

Logo, pode-se deduzir que a maioria da população está à parte do conhecimento sobre Astronomia. Torna-se, então, necessário que mecanismos sejam criados para o enfrentamento desta discrepância acerca de um conhecimento tão antigo, entretanto atual, que permeia toda a história da civilização.

Refletindo sobre tais colocações, neste texto buscamos expor as ações que foram desenvolvidas na cidade de Uberaba/MG, mostrando as diversas possibilidades que a Astronomia proporciona para o desenvolvimento de uma cultura científica, com foco interdisciplinar, em espaços não formais de educação, alcançando não apenas estudantes de escolas públicas, mas com potencial de educar cientificamente pessoas de diferentes faixas etárias e estratos sociais.

\section{As potencialidades do Ensino de Astronomia}

Em documentos bases da educação brasileira, como os Parâmetros Curriculares Nacionais (PCN), é dado o foco para a formação do indivíduo, que após ter concluído a educação básica, possa compreender e participar dos fatos de seu cotidiano, ou seja, entender-se como um indivíduo que participa e é integrante desse Universo que 
lhe contém (BRASIL, 1997). A Astronomia pode contribuir com este cenário, por exemplo, em um contexto filosófico com as representações de temporalidade para o homem.

É da cultura que nascem concepções de tempo tão diferenciadas como o tempo mítico, escatológico, cíclico, cronológico, noções sociais criadas pelo homem para representar as temporalidades naturais, expressas nos tempos geológico e astronômico. Não se pode esquecer, ainda, que mesmo o tempo natural se reveste de um caráter cultural, quando apropriado pela Geologia e pela Astronomia, enquanto ciências socialmente criadas. [...] As sociedades agrárias organizaram a vida cotidiana pelo tempo cíclico, fixado pelos momentos da plantação e da colheita e pelas estações que se repetem anualmente, e vincularam o tempo cotidiano, com seus ritmos de mudanças, ao astronômico, criando calendários, referenciando as marcas dos acontecimentos diários e daqueles considerados significativos para a memória coletiva (BRASIL,1998b, p. 23-24).

A utilização da Astronomia nos possibilita uma abordagem interdisciplinar com os demais componentes curriculares, sejam das Ciências da Natureza ou das Ciências Humanas. Essa interdisciplinaridade é um dos focos do PCN, sendo que:

Nessa nova compreensão do ensino médio e da educação básica, a organização do aprendizado não seria conduzida de forma solitária pelo professor de cada disciplina, pois as escolhas pedagógicas feitas numa disciplina não seriam independentes do tratamento dado às demais, uma vez que é uma ação de cunho interdisciplinar que articula o trabalho das disciplinas, no sentido de promover competências. As linguagens, ciências e humanidades continuam sendo disciplinares, mas é preciso desenvolver seus conhecimentos de forma a constituírem, a um só tempo, cultura geral e instrumento para a vida, ou seja, desenvolver, em conjunto, conhecimentos e competências. Contudo, assim como a interdisciplinaridade surge do contexto e depende da disciplina, a competência não rivaliza com o conheci- 
mento; ao contrário, se funda sobre ele e se desenvolve com ele (BRASIL, 1998a, p. 13).

Neste aspecto, a interdisciplinaridade com enfoque na Astronomia, pode ser utilizada em diversas disciplinas como: Português, Química, Biologia e Sociologia (LANGHI e NARDI, 2009). Assim, como a interdisciplinaridade pode ser utilizada em sala de aula, também pode fazer parte das ações desenvolvidas em espaços não formais de educação, como planetários e observatórios astronômicos. Essa interação com outras disciplinas desvincula a Astronomia como um conhecimento especificamente ligado à Física, e contribui para desconstruir a conceituação de caixas estanques, de áreas do saber que não se comunicam. Ainda que, em um aspecto organizacional, o ensino seja separado em disciplinas, é de suma importância ensinar os conteúdos das diversas áreas do conhecimento buscando uma interligação entre eles:

Entender como o ser humano vem se utilizando e se apropriando do mundo natural exige o estabelecimento de relações entre os muitos campos do saber, de maneira que o olhar da Química não exclui, ao contrário, necessita de constante interação com conhecimentos da Biologia, Astronomia, Física, História, Geografia, Geologia e até mesmo da Economia, Sociologia e Antropologia (BRASIL, 2002, p. 94).

O caráter interdisciplinar da Astronomia pode proporcionar aos alunos um olhar mais amplo, eliminando a ideia de fragmentação dos conhecimentos (DIAS e RITA, 2008). Apesar de temas de Astronomia estarem presentes nos PCN, verifica-se que estas temáticas acabam não sendo adotadas na educação básica ou, ainda, são "diluídas homeopaticamente" durante os anos escolares. Este fato culmina em alunos saindo da escola sem um conhecimento mínimo de assuntos ligados à Astronomia e sem conseguir relacioná-la ao seu cotidiano (LANGHI e NARDI, 2009; DIAS e RITA, 2008). 
Um caminho para a realização das atividades de Astronomia em sala de aula pode estar na utilização da Divulgação Científica (DC) visando, inclusive, à promoção da alfabetização científica dos alunos. Entendemos o termo DC como a utilização de uma linguagem adequada da Ciência e Tecnologia para o cidadão comum, de modo que os fatos relacionados à ciência possam ser interpretados com princípios científicos e não com ideias desconexas e de senso comum (BUENO, 2007). Segundo Reis (1964), a DC possui duas funções que se complementam: a de ensinar, ampliando a função da escola, e a de estimular o desejo de aprender no indivíduo. Tais funções se assemelham em estruturas de educação não formal, realizadas em planetários e museus de ciências, por exemplo.

Frente ao exposto, torna-se evidente que a Astronomia é uma temática que tem inúmeras possibilidades de trabalho na educação formal e não formal. Essa temática permite aos educadores desenvolver um trabalho interdisciplinar, que permita ao aluno ter uma visão do Universo que o cerca de maneira mais abrangente. $\mathrm{O}$ acesso a materiais referentes à Astronomia se tornou mais fácil hoje, facilmente nos deparamos com sites, vídeos, livros e revistas que abordam os mais diferentes tópicos relativos a este assunto. Sabe-se que, na atualidade, o conhecimento dos alunos referentes às ciências não é construído apenas na escola mas sim, em grande volume, em vários meios de divulgação científica (AROCA e SILVA, 2011).

A aprendizagem ocorre constantemente, seja na escola, nos museus, em centros de ciência ou em conversas com amigos, nas mais variadas formas e perspectivas. No entanto, diante do grande número de informações disponíveis na contemporaneidade, é necessário saber selecionar e ter um olhar crítico para eles, uma vez que é comum conceitos errôneos serem socializados. Assim, os museus de ciência possuem um importante papel na disseminação do conhecimento científico e, também, na desmistificação de conhecimentos errôneos (AROCA e SILVA, 2011; SCHIVANI, 2010). Entendemos que um dos principais aspectos desses espaços está no despertar a motivação do visitante para 
a ciência, ao oferecer ambientes propícios à comunidade para que esta tenha a oportunidade de tomar contato com, por exemplo, instrumentos e práticas científicas (AROCA e SILVA, 2011; LANGHI e NARDI, 2009).

As principais ações de divulgação científica, em um viés da Astronomia, desenvolvidas por esses espaços, compreendem palestras, exposições, observações dos astros e visitas a planetários. Cada uma dessas vertentes tem sua importância na disseminação do conhecimento. As observações dos astros por meio de um telescópio, por exemplo, podem ocorrer em períodos noturno ou diurno. No entanto, em observações diurnas, é recomendado que, ao se observar o Sol, se utilize lentes com filtro $\mathrm{H}$-alpha, de modo a realizar a visualização com segurança.

Acrescenta-se que, para a visualização do céu, é possível recorrer às ferramentas computacionais que auxiliem o trabalho de localização e identificação dos astros. Um exemplo é o software Stellarium, um programa de computador livre disponível para MacOS, Windows e Linux, e também em aplicativo de celular pago, para Android e iOS. Este aparato permite a simulação do céu noturno, no qual é possível identificar as constelações, a Lua e outras estruturas celestes (ZOTTI e WOLF, 2018). Outra ferramenta computacional para o trabalho e divulgação da Astronomia é o aplicativo de celular Google Sky Map. Este aplicativo utiliza o sistema de GPS do smartphone para indicar na tela do aparelho as localidades dos astros no céu.

A partir de um olhar escolar, podemos assumir que as atividades promovidas pelos museus de ciências, em especial sobre o tema Astronomia, trazem grandes contribuições às ações realizadas na educação formal, escolar. Além disso, as atividades citadas atuam como um chamativo para o público visitar os museus e centros de ciências, podendo instigar as pessoas na busca por mais informações sobre o tema. A seguir, apresentaremos e discutiremos ações no âmbito da Astronomia realizadas na cidade de Uberaba, Minas Gerais. O intuito consistiu em apresentar possibilidades de se trabalhar com a temática 
Astronomia em diferentes ambientes, espaços de educação não formal, como museus e centros de ciência, além de espaços formais da educação, como Universidades e escolas de educação básica.

\section{Ações interconectadas de Astronomia em Uberaba/MG}

As primeiras atividades apresentadas nesta comunicação remontam ao ano de 2011, sendo realizados dois cursos de férias na Universidade Federal do Triângulo Mineiro (UFTM), denominados "Introdução à Astronomia e Astrofísica". Embora os cursos tenham sido direcionados à comunidade externa à Universidade, por tratar-se de proposta de natureza extensionista, notou-se grande afluxo de estudantes da UFTM de diversos cursos, além de professores da rede pública de ensino. Na ocasião não havia na matriz curricular dos cursos de licenciatura oferecidos pela universidade qualquer disciplina que abordava Astronomia e, portanto, uma total ausência de discussões sobre esta temática no âmbito da formação de professores.

Nos dois cursos foram disponibilizadas 60 vagas, sendo todas preenchidas e gerando uma lista de espera, fato que evidencia o interesse da comunidade por estas questões. Estas primeiras atividades imprimiram a necessidade de disseminar os conhecimentos deste campo à população uberabense. Em 2012 houve uma reestruturação curricular do curso de Licenciatura em Física da UFTM e duas disciplinas de Astronomia foram inseridas no currículo (uma obrigatória e outra eletiva), buscando contribuir para superar o déficit de conhecimentos sobre Astronomia na formação de professores, neste caso da área de Física. Como relatado por Roberto Junior, Reis e Germinaro (2014, p. 99),

[...] são muito poucos os cursos de Licenciatura em Física que possuem a disciplina de Astronomia na estrutura curricular, mais precisamente apenas $15 \%$ da amostra. [...] Isso significa que os cursos de Licenciatura em Física estão entregando para a sociedade professores sem uma formação mínima necessária para ensinar os conteúdos básicos de Astronomia. 
Convém ressaltar que com o trabalho sobre conceitos de Astronomia com os futuros professores espera-se disseminar esse conhecimento no âmbito da sociedade, de modo a potencializar o aumento de atividades formais e não formais sobre o tema na região de abrangência da UFTM. Ainda no ano de 2012, foi possível por meio do Programa Institucional de Bolsas de Iniciação à Docência (PIBID), introduzir discussões de Astronomia para os alunos do Ensino Médio de duas escolas parceiras, por meio de um curso preparatório para a Olimpíada Brasileira de Astronomia (OBA). Este curso teve elevada procura pelos estudantes, havendo mais de 100 inscritos e 60 concluintes.

Em 2013, ocorreu a realização pela primeira vez de uma visualização do céu com telescópio, contando com a presença da comunidade interna e externa à UFTM. Destacamos a presença de cerca de 60 pessoas com variadas faixas etárias nesta atividade. Inclusive alguns participantes levaram seus próprios instrumentos de visualização do céu (lunetas e telescópios), aumentando o grau de integração entre os presentes. Foi um excelente momento de troca de conhecimentos. $\mathrm{Na}$ ocasião o intuito foi a não hierarquização de conhecimento, tomando consciência das diversas facetas do conhecimento trazido pelos participantes, geralmente ligados ao senso comum e com concepções alternativas, mas as inspiramos a pensar de modo indissociável entre as componentes científica, cultural e filosófica.

Neste mesmo ano, mas com culminância em 2014, foram iniciados estudos investigativos sobre as concepções dos professores do Ensino Fundamental sobre Astronomia, interligando suas concepções com conceitos errôneos persistentes sobre Astronomia em livros didáticos. Foi notado neste estudo que os professores desconhecem os conceitos físicos que ocasionam muitos fenômenos relacionados à Astronomia. Inter-relacionando os conteúdos dos livros didáticos e o conhecimento dos professores observou-se que muitos erros conceituais dos professores podem ser decorrentes dos erros dos livros didáticos, implicando na forte influência do livro sobre o professor. Com esta 
percepção, ainda em 2014, propusemos um curso de extensão com 20 horas de duração à comunidade externa à UFTM, tendo como foco professores, em especial aqueles atuantes na área de Ciências da Natureza.

Ressaltamos que o conteúdo de Astronomia, em geral, não é ensinado na maioria dos cursos de formação de professores de ciências, a exemplo dos cursos de Licenciatura em Ciências Biológicas sendo, portanto, fundamental introduzir estes professores às temáticas de Astronomia. De igual modo, acreditamos que, ao ensinar conceitos adequados aos professores de ciências, potencializa-se o desenvolvimento de atividades de Astronomia com os estudantes nas escolas. No sentido de minimizar essa distorção, em 2018, o curso de Licenciatura em Ciências Biológicas oferecido pela UFTM passou a contar com uma nova matriz curricular, na qual foi incluída uma disciplina eletiva de Introdução à Astronomia. Trata-se de um ganho para a instituição uma vez que supre, ao menos nesta instituição, parte das lacunas na formação desses futuros professores de Ciências, atendendo ao disposto pelo relatório anual do Instituto Nacional de Ciência e Tecnologia, em seu Núcleo de Astrofísica (INCT, 2009).

Em 2015, foi criado o Clube de Astronomia de Uberaba, com vistas a possibilitar a apresentação de palestras com temáticas diversas sobre Astronomia e áreas correlatas para a população. O clube, sob a coordenação do Prof. Dr. Marcos Dionizio Moreira, do Departamento de Física da UFTM, reuniu-se na Biblioteca Pública Municipal Bernardo Guimarães todas as sextas-feiras no período da tarde. Desde o início das atividades, estas tiveram a participação de estudantes de cursos de graduação da UFTM, bem como de professores e estudantes da rede estadual de ensino. Também neste ano foi montada uma exposição de imagens astronômicas na Biblioteca, com banners procedentes do Ano Internacional de Astronomia (2009), doados por um antigo organizador de um Clube de Astronomia em Ituverava-SP (Sr. José Fernando Meneghini dos Santos). 
Ainda em 2015, buscando trabalhar a temática Astronomia em uma vertente diurna, foi proposto no âmbito de um edital $\mathrm{CNPq}^{1} \mathrm{um}$ curso teórico-prático sobre a "Física Solar". O objetivo foi discutir temáticas relacionadas ao Sol, às estrelas e realizar observações diurnas do céu. O público-alvo foi composto por professores da rede estadual e municipal de ensino, tendo a participação de 20 pessoas, além de estudantes do curso de Licenciatura em Física da UFTM e que já atuavam em escolas públicas da cidade. Algumas das atividades práticas realizadas utilizaram-se de materiais de baixo custo e foram elaboradas no sentido de instrumentalizar os participantes para replicá-las em salas de aula com seus alunos. Dentre as atividades desenvolvidas, estão medição da temperatura da fotosfera solar, criação de animações do tipo stop motion, visualização de manchas solares e do céu noturno, bem como a construção de um espectroscópio amador.

Ampliando nossas ações, em 2015 foi submetida à Fundação de Amparo à Pesquisa do Estado de Minas Gerais (FAPEMIG) uma proposta de programa de divulgação científica para a compra de um planetário itinerante ${ }^{2}$. A proposta, aprovada em julho de 2016, intitulada "Para além dos muros da universidade: a divulgação científica por meio de ações socioeducativas e culturais" (FAPEMIG APQ-0399015), visava ao fortalecimento de ações de popularização da ciência, da tecnologia e da inovação, estando alicerçado no desenvolvimento de ações integradas: "Memórias do passado: Geologia e Paleontologia e sua relação com a sociedade"; "O clube de Astronomia como promo-

\footnotetext{
${ }^{1}$ Esta ação integrou o projeto de pesquisa intitulado "Inovar e contextualizar o ensino: inser ção e investigação do ensino de física solar no ensino médio", financiado pelo CNPq (Proces so: 459824/2014-7) e coordenado pelo Prof. Dr. Pedro Donizete Colombo Junior, em colaboração com os professores Silvia Calbo Aroca (UFRN), Ariane Baffa Lourenço (UFGD), Cibelle Celestino Silva (USP) e Marcos Dionizio Moreira e Daniel Fernando Bovolenta Ovigli (UFTM).

${ }^{2}$ O planetário itinerante foi adquirido por meio de uma chamada pública da FAPEMIG para ações de Divulgação Científica (DC), sendo parte integrante de um programa de divulgação científica cadastrado na UFTM sob o número PROEXT/SIGProj: 245444.1298.242645.26082016, $\mathrm{n}^{\circ}$ 310/2016. O projeto tem gestão dos professores Pedro Donizete Colombo Junior (coordenador), Daniel Fernando Bovolenta Ovigli, Marcos Dionizio Moreira e Thiago Marinho, além de 18 discentes de graduação dos cursos de licenciatura em Física, Matemática e Ciências Biológicas, 3 estudantes da Educação Básica.
} 
tor de popularização da ciência e tecnologia em diferentes vertentes"; "A Física solar: uma abordagem interdisciplinar e contextualizada para a popularização da ciência, da tecnologia e da inovação", "Exposições de Astrofísica e Paleontologia - olhando para o céu e visualizando o passado", e "Feiras e mostras científicas: superando os limites disciplinares e vislumbrando a comunicação pública da ciência e da tecnologia para além dos muros da Universidade”. Tais ações foram pensadas atentando-se para o caráter multidisciplinar e integrador frente à tríade ensino-pesquisa-extensão da Universidade, tendo objetivos comuns de popularização do conhecimento e o atendimento de um público diversificado.

Com a aprovação do programa, em 2016, este passou a nortear as ações de Astronomia desenvolvidas na UFTM. O fomento para a compra do Planetário e outros itens foi efetivamente liberado no final de 2017 porém, mesmo frente a este cenário, as ações tiveram início em 2016. Neste período foram promovidas sessões semanais no Clube de Astronomia, em parceria com a Biblioteca Municipal, Mostras de Saberes nas Escolas Estaduais Minas Gerais e Francisco Cândido Xavier, exposições de banners na UFTM, no Sesc, em escolas da rede estadual e em um shopping da cidade de Uberaba.

No período compreendido entre o segundo semestre de 2016 e todo o ano de 2017, foram desenvolvidas as seguintes palestras no clube de Astronomia: "Importância da Astronomia para humanidade: contemplando o céu”; "A Lua na vida no/do campo: relações e dissensões entre o conhecimento científico e tradicional"; "Mitos cosmogônicos e a construção do conhecimento científico"; "As Plêiades, a arte e a Astronomia"; "O conhecimento lunar e as crenças populares"; "Fontes confiáveis na internet sobre Astronomia"; "O que as pessoas querem saber sobre Ciência?"; "Astronomia no cotidiano"; "Uso de projetos de Astrofísica”; "Escalas do Universo"; "Teorias sobre a origem da água em nosso planeta"; "Influências extraterrestres na vida da Terra?"; "Olimpíada Brasileira de Astronomia: o que é e como participar"; "Tempestades solares"; "Astrobiologia e vida extraterrestre"; 
"Raios cósmicos - origem, detecção e perigo"; "Quem conta um conto aumenta um ponto"; "Astrofísica em um projeto de extensão"; "Escalas do Universo - Partes 1 e 2"; "Calendários"; "Astronáutica no Brasil"; "O desenvolvimento da Astronáutica na Guerra Fria e seus desdobramentos atuais"; "Os campos de pesquisa em Astronomia"; "As pseudo-influências dos astros"; "Ciência e Música"; "Mitos da Lua e o lobisomem" e "O Big Bang e a radiação cósmica de fundo". Tais palestras foram apresentadas de maneira expositivo-dialogada, com a realização de perguntas durante e após as apresentações. Os palestrantes foram professores e estudantes de diferentes cursos de licenciatura da UFTM, dentre eles alunos da disciplina de Astronomia I do curso de Física. O público participante foi muito variado, contemplando alunos da educação básica, universidades e público em geral (comunidade externa à UFTM).

As ações realizadas até o momento permitem afirmar a integração acadêmica, articulando ensino, pesquisa e extensão: palestras trabalhadas no clube de Astronomia foram discutidas em sala de aula na Universidade, em especial no curso de Licenciatura em Física, nas disciplinas "Estudos e Desenvolvimento de Projetos I" e "Astronomia I", havendo concordância com Benetti, Souza e Souza (2015, p.26) que mencionam "a extensão possibilita o enriquecimento da experiência discente em termos teóricos e metodológicos”. Esta vivência dos alunos no curso de Licenciatura em Física, na integração entre atividades de extensão e disciplinas na graduação, atende às demandas levantadas pela "creditação da extensão universitária", criado pelo Plano Nacional de Educação (BENETTI, SOUZA e SOUZA, 2015).

Desde sua inauguração participaram do Clube de Astronomia mais de 300 pessoas, entre público escolar (educação básica e superior) e visitantes espontâneos. Foi possível abranger um público heterogêneo, desde crianças com idade de 6 anos a idosos com idade superior a 65 anos. Destaca-se, também, a participação de salas de aulas trazidas por alunos de iniciação à docência (ID) do (PIBID/UFTM), em especial do subprojeto Física. 
Dentre as atividades desenvolvidas pelo Clube de Astronomia estava a divulgação permanente. Para isso os participantes da equipe realizaram visitas às escolas públicas da cidade com o intuito de divulgar o clube, tendo em vista captar mais participantes. Nessas ações primeiramente é apresentado o objetivo do clube e realizada, com autorização da direção da escola, uma exposição de banners de Astronomia, além da divulgação da agenda de palestras, dentro do ano letivo/escolar com a divulgação de seus respectivos temas e horários.

Extrapolando os limites físicos do clube, a partir do segundo semestre de 2017, com a participação de novos membros (bolsistas e voluntários) na equipe (estudantes dos cursos de licenciatura em Física, Matemática e Ciências Biológicas e da educação básica), ações foram ampliadas. Foi possível realizar palestras em 4 escolas da cidade de Uberaba, sendo elas: Escola SESC, E.E. Santa Terezinha, E.E. Minas Gerais e E.E. Quintiliano Jardim, alcançando um público de cerca de 610 pessoas. Além disso, foram realizadas palestras no bairro rural de Peirópolis, também situado no município e também para um grupo de estudantes da cidade de Monte Carmelo-MG, que estavam em excursão pela cidade. Uma fanpage no Facebook foi criada no sentido de amplificar a divulgação do clube para Uberaba e região. Está página também se destina a divulgar assuntos diversos relacionados às Ciências, atentando sempre para a idoneidade da fonte divulgadora. A página atualmente possui 779 seguidores, que acompanham as publicações sobre as novidades no mundo da Astronomia e afins e tiram suas dúvidas por meio do chat.

Em 2017, também foi iniciada a atividade “A Astrofísica por meio de exposições itinerantes", com a finalidade de desenvolver exposições centradas na Astronomia e na Astrofísica como forma de popularizar a ciência. A exposição contém aproximadamente 40 pôsteres, todos apresentam uma imagem relacionada aos temas citados acima, com breve descrição sobre o objeto estudado. Durante o ano de 2017, foram realizadas 09 (nove) exposições em diferentes locais da cidade de Uberaba: Shopping Uberaba, Instituto de Ciências Exatas, Na- 
turais e Educação (ICENE - UFTM), escolas particulares, Biblioteca Municipal de Uberaba, Escola Sesc em Uberaba e Complexo Cultural e Científico de Peirópolis (CCCP). Por estas exposições passaram públicos bastante diversificado, totalizando mais de 2.050 visitantes.

No que tange à observação do céu noturno, em 2017 ocorreram 4 visualizações com telescópio no campus Univerdecidade UFTM, possibilitando à comunidade local/interna a oportunidade de participar de atividades de Astronomia com o uso de telescópio, havendo média de 25 pessoas por evento. Buscamos uma linguagem de fácil acesso, discutindo a Astronomia em um viés interdisciplinar, pois participaram das atividades técnicos-administrativos, professores e estudantes dos cursos de Licenciatura em Ciências Biológicas, Física, Química, Matemática e Educação do Campo ofertados pela universidade. Também foram realizadas visualizações em Peirópolis sem a utilização de telescópio, com a finalidade de observar o céu noturno e, na ocasião, a ocorrência da chuva de meteoros Delta-Aquarídeas. No segundo semestre de 2017, as condições climáticas inviabilizaram a grande maioria das visualizações agendadas, ocasionando apenas três visualizações noturnas no Campus II da UFTM, com média de 20 pessoas por atividade.

A partir de 2018, os esforços na DC sobre Astronomia centraram-se em atividades de extensão desenvolvidas no CCCP, de modo a diversificar as atividades desenvolvidas naquele espaço. Assim, as atividades do Clube de Astronomia, visualização do céu e exposição de Astrofísica foram deslocadas para as instalações do CCCP. A exposição de Astrofísica passou a ter caráter permanente e passa a ser parte do acervo, que até então também estava restrito a exposições ligadas à Paleontologia. A necessidade da presença constante de mediadores no complexo nos instigou a reestruturar as atividades dos bolsistas e voluntários que participavam das atividades ligadas à Astronomia, acrescentando às suas atividades também a mediação das exposições paleontológicas, assim como os estudantes que mediavam apenas assuntos relacionados à Paleontologia passaram a mediar também a exposição 
de Astrofísica. Para isso todos os estudantes passaram por treinamentos nas duas áreas de mediação. A troca de experiências entre os estudantes, com diferentes formações e vivências, criou uma perspectiva interdisciplinar rica e vibrante. As conexões entre Física, Astronomia, Astrofísica, Biologia, Paleontologia, dentre outras, ficaram evidentes, sobrepujando qualquer forma tradicional de ensino conteudista multidisciplinar.

As visualizações do céu foram pensadas com periodicidade mensal no CCCP, havendo duas palestras motivacionais apresentadas no anfiteatro ("O que ver no céu” e "Astronomia no Cotidiano") no início de cada sessão de visualização. Também introduzimos uma formação, no modelo de minicurso, sobre o uso do software Stellarium, sendo este projetado no ambiente externo do CCCP.

Enfim, no segundo semestre de 2018, com a aquisição do planetário, foram iniciadas as sessões de Astronomia no CCCP, tendo atendido entre os meses de outubro e dezembro aproximadamente 950 visitantes, espontâneos e escolares. Atualmente, o planetário encontra-se em itinerância por diferentes locais, como Universidade e escolas de Uberaba, de modo a atender a um público eclético e cumprir a função de popularização do conhecimento científico. Outras informações sobre esta ação podem ser consultadas na página do Grupo de Estudo e Pesquisa em Educação Não Formal e Ensino de Ciências $(\text { GENFEC) })^{3}$.

\section{Considerações Finais}

Diante do exposto, pode-se observar que as atividades desenvolvidas ao longo desses anos permitiram contribuir com a diminuição das lacunas quanto a informações sobre a Astronomia e áreas correlatas, em Uberaba e região. Desde o início, as ações realizadas foram

\footnotetext{
${ }^{3}$ O Grupo de Estudo e Pesquisa em Educação Não Formal e Ensino de Ciências (GENFEC) tem trabalhado na interface Formação de Professores, Educação Não Formal, Divulgação Científica e Ensino de Ciências. Para informações relativas ao Planetário, acesse https://genfec.com.br/planetario-itinerante/
} 
pautadas no princípio da DC, buscando alcançar espaços não formais de educação, mas não excluindo as possibilidades encontradas em espaços formais.

Baseado no conceito de interdisciplinaridade, a Astronomia foi abordada como uma ciência abrangente e multifacetada, construída a partir do escopo de conhecimentos de diversas áreas de conhecimentos. Ao longo dos anos, na busca por alcançar todos os estratos socioeconômicos/culturais/educacionais/etários, as atividades foram apresentadas em escolas públicas (centrais e periféricas) e privadas, incluindo Ensino Fundamental e Ensino Médio, biblioteca municipal, shopping center, universidade e CCCP. Este último desempenhou importante papel de disseminação dos conhecimentos de Astronomia para além da região de Uberaba-MG, uma vez que conta com a visitação de milhares de pessoas por ano de diversos locais do Brasil e do mundo.

No que se refere ao espaço universitário, guiados pela prerrogativa da indissociabilidade ensino/pesquisa/extensão, diferentes disciplinas foram contempladas com as ações dos projetos e programas explicitados ao longo da presente comunicação, sempre utilizando-se de referencial teórico-metodológico de pesquisas científicas para construção das propostas. Ademais, destaca-se a socialização dos conhecimentos produzidos por meio de relatos de experiências e artigos que foram publicados em diferentes meios, como o Simpósio Nacional de Ensino de Física, Encontro Sul-Mineiro de Ensino de Física, Simpósio Nacional de Educação em Astronomia, Encontro Nacional de Astronomia; além do desenvolvimento de projetos de Iniciação Científica e artigos científicos de periódicos da área de ensino e educação.

As vivências, experiências e conhecimentos construídos pelos estudantes da educação básica e de graduação, participantes das atividades como bolsistas e voluntários, são imensuráveis. Estudantes que no decurso de sua formação conseguiram participar ativamente dessas atividades construíram, de maneira inequívoca, um cabedal de conhecimentos e valores que lhes permitem transpor as dificuldades ineren- 
tes do ensino tradicional que ainda persiste na prática de professores das redes públicas de ensino. Os resultados alcançados em todos os âmbitos dos projetos e programas de DC, seja na divulgação da ciência ou na formação de recursos humanos, possibilitam afirmar as ações desenvolvidas trilharam o caminho certo! O histórico aqui apresentado nos transborda de alegria e satisfação diante do passado, presente e perspectivas.

\section{Referências}

AROCA, S. C. e SILVA, C. C. Ensino de astronomia em um espaço não formal: observação do Sol e de manchas solares. Revista Brasileira de Ensino de Física, v. 33. n. 1, 1402, 2011.

BATISTA, M. C. Redescobrindo o Céu. Astro Nova, n. 4, p. 35-41, 2014.

BENETI, P. C.; SOUZA, A. I. e SOUZA, M. H. N. Creditação da extensão universitária nos cursos de graduação: relato de experiência, Revista Brasileira de Extensão Universitária, v. 6, n. 1, p. 25-32, 2015.

BRASIL. Ministério da Educação. Secretaria de Educação Básica. Parâmetros Curriculares Nacionais: Ciências Naturais. Brasília (DF), 1997. . Ministério da Educação. Parâmetros Curriculares Nacionais para o Ensino Médio: Ciências da Natureza, Matemática e suas Tecnologias. PCN Ensino Médio. Brasília: MEC, 1998a.

. Ministério da Educação. Parâmetros Curriculares Nacionais: Ciências Humanas e suas Tecnologias. Brasília (DF), 1998b.

Ministério da Educação. Orientações Educacionais Complementares aos Parâmetros Curriculares Nacional para o Ensino Médio. PCN+. Brasília: MEC, 2002.

BUENO, W. C. Jornalismo científico. (Editorial). Portal do Jornalismo Científico, 2007. Disponível em: <http://www.jornalismocientifico.com.br/jornalismocientifico/conceitos/jornalismocientifico.php.> Acesso em: 27 out. 2018. 
DIAS, C. A. C. M. D. e RITA, J. R. S. Inserção da astronomia como disciplina curricular do ensino médio, Revista Latino-Americana de Educação em Astronomia - RELEA, n. 6, p. 55-65, 2008.

INSTITUTO NACIONAL DE CIÊNCIA E TECNOLOGIA EM ASTROFÍSICA (INCT-A). Relatório Anual, 2009. Disponível em: $<$ http://www.astro.iag.usp.br/ incta/Rel_Anual_2009/Relatorio_Anual_2009.pdf.> Acesso em: 23 mar. 2019.

LANGHI, R. e NARDI, R. Ensino da astronomia no Brasil: educação formal, informal, não formal e divulgação científica. Revista Brasileira de Ensino de Física, [S.1.], v. 31, n. 4, p. 4402-1-4402-11, jan. 2009. Disponível em: <http:// www.scielo.br/pdf/rbef/v31n4/v31n4a14.pdf. $>$ Acesso em: 27 out. 2018.

MILONE, A. C. et al. Introdução à Astronomia e Astrofísica. In: MILONE, A. C; et al. Curso de Introdução à Astronomia e Astrofísica. São José dos Campos: Instituto Nacional de Pesquisas Espaciais, 2010.

OLIVEIRA, E. F.; VOELZKE, M. R. e AMARAL, L. H. Percepção astronômica de um grupo de alunos do ensino médio da rede estadual de São Paulo da cidade de Suzano. Revista Latino-Americana de Educação em Astronomia RELEA, n. 4, p. 79-98, 2007.

REIS, J. A divulgação científica e o ensino. Ciência e Cultura, v. 16, n. 4, p. 352-353, 1964.

ROBERTO JUNIOR, A. J.; REIS, T. H. e GERMINARO, D. R. Disciplinas e professores de Astronomia nos cursos de licenciatura em Física das universidades brasileiras. Revista Latino-Americana de Educação em Astronomia RELEA, n. 18, p. 89-101, 2014.

SCHIVANI, M. Educação não formal no processo de ensino e difusão da astronomia: ações e papéis dos clubes e associações de astrônomos amadores. 2010. 173 p. Dissertação (Mestrado em Ensino de Ciências: modalidade Física). Universidade de São Paulo. São Paulo, 2010.

ZOTTI, G; WOLF, A. Stellarium 0.18 .2 user guide. [S. 1.], 15 ago. 2018. Disponível em: $<$ https:/github.com/Stellarium/stellarium/releases/download/ v0.18.3/stellarium_user_guide-0.18.3-1.pdf.> Acesso em: 24 fev. 2019. 